Hope College

Hope College Digital Commons

Faculty Publications

Fall 2017

\title{
Improving student assessments of elections: the use of information literacy and a course-embedded librarian
}

Todd J. Wiebe

Hope College, wiebe@hope.edu

Paula Booke

Tulane University, pbooke@tulane.edu

Follow this and additional works at: https://digitalcommons.hope.edu/faculty_publications

Part of the American Politics Commons, and the Information Literacy Commons

\section{Recommended Citation}

Repository citation: Wiebe, Todd J. and Booke, Paula, "Improving student assessments of elections: the use of information literacy and a course-embedded librarian" (2017). Faculty Publications. Paper 1443. https://digitalcommons.hope.edu/faculty_publications/1443

Published in: Learning and Teaching: The International Journal of Higher Education in the Social Sciences, Volume 10, Issue 2, Fall October 1, 2017, pages 83-106. Copyright @ 2017 Berghahn Journals, New York.

This Article is brought to you for free and open access by Hope College Digital Commons. It has been accepted for inclusion in Faculty Publications by an authorized administrator of Hope College Digital Commons. For more information, please contact digitalcommons@hope.edu. 


\title{
Improving student assessments of elections The use of information literacy and a course-embedded librarian
}

\begin{abstract}
The study of U.S. elections as a part of introductory political science courses has become an increasingly difficult endeavour as students encounter the ever-changing landscape of electoral politics. Instructors seeking to equip students with the skills needed to navigate this complex terrain may look for partnerships with library faculty and staff as a means of bridging the research gap faced by students in these courses. This article examines the efficacy of a course-embedded librarian and information literacy training as a means of increasing student research confidence and competence. The findings of our quasi-experiment suggest that students participating in a course with an embedded librarian, information literacy training and an assignment based on the training session reported higher levels of research confidence and demonstrated the use and understanding of selected information literacy skills and concepts.
\end{abstract}

Keywords: elections, information literacy, Internet research, political science, politics, undergraduate students

This is a preprint of an article whose final and definitive form has been published in Learning and Teaching @ 2017 Berghahn; available online at: http://www.berghahnjournals.com/view/journals/latiss/10/2/latiss100207.xml 


\section{Politicking in the digital age}

The study of elections is a core element of the discipline of political science and an important component of introductory courses. This course content provides students with opportunities to encounter and discuss core principles such as citizenship and political tolerance. However, studying ongoing elections in the context of introductory courses is becoming more difficult. As campaigns increasingly rely more on information technologies to raise funds, communicate their message and mobilise their bases, the technological tools and skill sets that students must use to analyse elections become more complicated. Increasingly these core goals cannot be achieved without the integration of information technologies in the classroom. From microtargeting voters through mobile devices (Corasaniti and Parker 2014) to voter use of social media platforms to obtain election information (Smith 2014), the 2014 U.S. midterm election underscored the integration of web-based technologies in electioneering efforts. The consequence is an increase in the pace at which elections and the commentary surrounding them move and a shift in the role that the academic canon plays in student analysis of elections. Students engaged in an evaluation of an ongoing election must rely less on traditional sources of quality information and more on information they gain from digital sources.

In the digital age, students are deluged with information from myriad sources. To produce students capable of navigating and understanding the new digital environment, information literacy (IL) must become a central component of teaching students to be informed consumers in elections. IL is assumed to improve the effectiveness of student searches, improve analysis and interpretation of information, and improve problem solving and decision-making (Webber and Johnston 2000). Empirical tests of the impact of IL training have suggested that this intervention can have significant outcomes for student understanding; improving the quality of 
the sources students draw on and greater confidence in their research skills (Gilbert, Knutson and Gilbert 2012). Assessments of the effects of this training have focused on myriad issues such as improving student research papers (Williams, Goodson, and Howard 2006).

\section{Librarians and information literacy in higher education}

Just as the information landscape has undergone exponential change with the technological boom - namely the Internet - of the past two decades, so too has the role and pedagogical interests of academic librarians. Long considered to be the keepers, organisers and preservers of information, academic librarians now also strive to be teachers of information. In higher education, librarians can be largely credited for bringing 'information literacy' to the forefront as an essential learning outcome and core competency for today's students. In 2000, the Association of College and Research Libraries (ACRL) unveiled its landmark Information Literacy Competency Standards for Higher Education, which have since played an integral part in framing IL initiatives at academic institutions of all types. Here, IL was defined by quoting the American Library Association's 1989 Presidential Committee on Information Literacy, stating that 'Information literacy is a set of abilities requiring individuals to "recognize when information is needed and have the ability to locate, evaluate, and use effectively the needed information"' (ACRL 2000). Rather vague, this definition leaves much open to interpretation and debate. Indeed, defining IL has been a topic of seemingly constant scrutiny (Kapitzke 2003; Owusu-Ansah 2003). Kapitzke asserts that that the meaning of IL has 'never been monolithic or fixed' and that 'no consensus on its theoretical or practical dimensions has emerged' (2003: 42). Yet, despite the ongoing tussle surrounding IL's defined parameters and purpose in higher education, academic librarians have remained committed to embracing a role shift and taking their unique skillsets, historically 
confined to physical library collections, and applying them to the expanse of the greater information environment.

For academic librarians with teaching responsibilities, this shift has meant recasting traditional ‘bibliographic instruction' or 'library user education' into 'information literacy education'. Traditional library instruction places little emphasis on higher-order skills or concepts that could be seen as useful or relevant outside the confines of a singular assignment or information need. Such instruction, as Gibson (2008: 12) describes, is 'inherently reactive, limited, and constrained', able only to achieve 'the limited goal of addressing episodic or occasional learning about scholarly or other information'. While the fundamentals of using an academic library remain an important and necessary element of the undergraduate curriculum, IL-centred instruction aims to nurture habits and skills with broader purposes and which may be applicable in multiple scenarios. Recently, there has been an increase in literature examining IL through the lens of critical theory and pedagogy in an effort to deemphasise the more pragmatic and functionalist aspects it had traditionally been stuck on (Tewell 2015). This is what is commonly known as ‘critical information literacy' (CIL). In 2015, an ACRL Task Force produced a Framework for Information Literacy for Higher Education, which is intended to be more flexible than the standards. Included in this document is an updated definition of IL which reads as follows:

Information literacy is the set of integrated abilities encompassing the reflective discovery of information, the understanding of how information is produced and valued, and the use of information in creating new knowledge and participating ethically in communities of learning (ACRL 2015). 
As noted by Spiranec, Zorica and Kos, 'the Framework makes a marked turn toward the reflective CIL sphere and in its central ideas bears a strong resemblance to views which were already expressed in earlier writings on CIL' (2016: 255). The framework consists of six 'frames' developed around key IL 'threshold concepts', which, together with the new definition, show a maturation of academic librarians' vision for IL. The six frames are:

- Authority Is Constructed and Contextual

- Information Creation as a Process

- Information Has Value

- Research as Inquiry

- Scholarship as Conversation

- Searching as Strategic Exploration

Examples of librarians working with other faculty colleagues to integrate IL learning objectives into a course or specific assignment have been well documented in the library and information science (LIS) literature and, to a lesser extent, in the discipline-specific literature. In the LIS literature, this type of collaboration is referred to as a form of 'embedded librarianship' (Butera, Gomes, and Kakar 2014; Daugherty and Russo 2013; Helms and Whitesell 2013; Knapp, Rowland, and Charles 2014; Pritchard 2010; Shumaker 2012). When librarians are embedded, they become an integral partner in the planning and/or teaching of a course or assignment. They are, as Shumaker (2009: 240) explains, 'a member of the customer community rather than a service provider standing apart'. Heightening librarians' role in this way makes them become more visible and accessible to students, and their contributions more apparent. 


\section{Political science and information literacy}

While, in essence, IL constitutes a repertoire of 'meta' skills or ways of thinking that transcend subject or course content, it is common to see IL outcomes aligned with those inherent to specific disciplines. In 2008, the Law and Political Science Section (LPSS) of ACRL put forth the 'Political Science Research Competency Guidelines', matching IL standards to the unique research and information needs of political science and related disciplines. These were drafted in such a way that encourages collaboration, indicating where the expertise of ' $F$ ' (faculty) or ' $L$ ' (librarian) would be especially valuable (LPSS 2008).

In the academic and professional literature, some of the more vocal advocates for integrating IL into the undergraduate political science curriculum are not librarians but political science faculty, thus suggesting a growing interest in IL outside of librarian circles. Nonetheless, this body of literature is small, and as Williams and Evans note, 'political science seems to lag behind other disciplines in incorporating IL education into its curriculum despite seeing a "logical fit and affinity" between the two' (2008: 117). Likewise, Alexander, upon sharing insights from students' use of sources and understanding of political information - particularly in his survey-level courses - contends that IL and 'political literacy' are 'inextricably linked and impossible to separate' (2009: 11). Thornton (2006, 2008, 2010, 2012) has written extensively on this topic, reporting on several instances where IL has been successfully integrated into the Politics curriculum at his home institution. Like others, he notes the co-extensiveness of the skills obtained in the process of becoming generally information literate and those that he would expect students to attain in his politics courses. 'To be a successful Politics student,' he writes, 'sufficient information literacy is a necessity' (Thornton 2008: 50). While acknowledging the 
evolving role of librarians and their work in the IL movement, Thornton contends that IL should be a joint effort - a partnership - and not confined to the library.

Examples of such collaborations have been represented in the literature, several of which specifically use ACRL's Information Literacy Competency Standards for Higher Education (Marfleet and Dille 2005; Stevens and Campbell 2008; Williams and Evans 2008) to design assignments and learning outcomes. In an article especially germane to the current study, Cope and Flanagan discuss how new media outlets such as blogs and social networks offer important up-to-date information as students follow and engage with political commentary and conversations. The authors assert how the Internet has become the 'preferred medium' for the dissemination and consumption of political information and therefore it is insufficient and unreasonable to restrict students' IL education to traditional 'reliable sources' such as those found in the library. The new media environment in which American politics is so thoroughly implanted is a 'chaotic blend' of varied content, and thus careful consideration must be given to the breadth of information available and how to assess the claims made on these platforms (Cope and Flanagan 2013: 5).

\section{Assessing the impact of information literacy on learning about elections}

This piece of research explores the impact of a course-embedded librarian on IL and on course content knowledge via the provision of in-class training, creation of assignments that marry research skill acquisition with course content acquisition, and assessment of student work. We hypothesise that the collaborative approach undertaken by joining the expertise of political science and library faculty will improve students' familiarity with and ability to assess the current state of campaigns and campaign finances, as well as information about candidate 
credentials. The research design utilises a quasi-experiment in which one of two comparable groups enrolled in an introductory American Government and Politics course was exposed to a course-embedded librarian, IL training and accompanying practicum assignment. Both groups completed a pre-test and post-test survey to gauge competency. The paper reports the findings of the intervention and its impact on competence among students. Experimental or quasiexperimental design accounts for a majority of the analysis done in the field (Koufogiannakis and Wiebe 2006). The analytical leverage offered by experiments has served as powerful tools to assess the efficacy of embedded librarians (Bowler and Street 2008).

Researchers recruited students from semester-long Introduction to American Politics and Government courses taught by two different faculty members at Hope College in Fall 2014. Both sections of the introductory course contained about 25 students, covered the same topics (such as the Constitution, interest groups and media as well as campaigns and elections) and met at generally the same time during the day. A total of 38 undergraduates completed all the elements of the study. First-year students made up 60.5 per cent of the sample. There were slightly more women (57.8 per cent) than men participants, with a higher proportion of women in the control group (61.1\%) compared to the experimental group (52.4 per cent). Student self-reported ideology varied. In the experimental group (also referred to as the treatment condition), 52.3 per cent of participants identified as liberal or extremely liberal, 23.8 per cent as moderate and 23.9 per cent as conservative or extremely conservative. By contrast, in the control group, 11.1 per cent identified as liberal, 55.6 per cent identified as moderate and 33.3 per cent identified as conservative.

Both groups of student participants undertook a pre-experiment and post-experiment survey. The pre-test and post-test surveys asked the same questions regarding students' self- 
assessed IL and election analysis competence. They included questions about student's familiarity with and confidence in searching for information online as well as their ability to evaluate the quality of the information they have found. Additionally, the survey tool assessed political sophistication by asking questions regarding their interest in politics, familiarity with elections in the United States and consumption of political information.

Students in the control group did not engage in IL training and had no course-embedded librarian. Their only exposure to election content came through course discussion on this topic. The treatment condition consisted of three components - a course-embedded librarian who along with a discipline specialist created course assignments and shaped course content, an IL training session and a practicum in which students practiced IL skills in the context of analysing six key Senate races in the 2014 midterm elections. Students completed the following assignment as a part of their practicum.

The course-embedded librarian and course instructor designed the practicum assignment that included three components. First, working in groups of five, students were asked to find ten web-based sources suitable for use in analysing the election contest. They were asked to catalogue these sources and offer a brief description of each, highlighting the originating point of the data and key links. These student-generated sources were then uploaded to the course guide on the library's website.

Following this research exercise, students were asked to write a one- to two-page summary describing their experience in finding the required sources. In the journal, students were encouraged to address issues such as: What strategies did you use to find the information? How did you evaluate the relative merit of their chosen sources? What technical problems did you have navigating this aspect of the assignment? Did you ask for help? 
The final component of the practicum was a pre-election and post-election report assignment. Students wrote a pre-election report utilising discipline-specific knowledge of elections gained through IL practices, such as polling data, campaign donation information and key social issues to assess the likelihood of electoral success of their chosen candidate. In the post-election report, students assessed the strength of the information in assessing the outcome of the election and reflected on larger national trends. These submissions were graded in tandem by the course instructor and the course-embedded librarian.

\section{Information literacy training}

An 80-minute class period - designed and led by a librarian - was devoted to exploring IL skills and concepts related to finding and using freely available online sources to research United States political information. This session took place early in the semester and coincided with students' being assigned to their groups and introduced to the mid-term elections lab project mentioned above. It began by assigning each group a popular political website to examine and report back to the class the type of content they found (for example, how it might be used for their particular research needs, what its best features are). This activity was intended to introduce students to some of the more well-known and comprehensive political websites but also to begin a discussion about how searches can and should go deeper than what is presented on such platforms. Much of the remaining time was spent by students working in their groups to examine a variety of web content such as newspapers (national and local), news aggregator sites, blogs (personal and professional), organisation and interest group websites, all while talking through a set of discussion prompts. Custom Google portals and advanced search options were also explored and demonstrated. Key concepts covered during the session included: 
- search term variation and flexibility, 'search input correlates with output'

- searching within a search - using the search boxes commonly found embedded in websites as localised search engines for specific content

- looking for citations or links to original sources or data tracking down primary data sources to verify the accuracy of how they were presented in secondary web content (data verification)

- identifying the purpose of various types of web content (for example, to simply inform/present data, to persuade or editorialise, to sell or solicit donations)

- making a habit of reading the 'About' sections of all sources as well as looking for information from other sources that might help in understanding the viewpoint of a particular organisation, interest group, news outlet, and so on.

- determining whether a website was commercial or non-commercial and why this might matter

- considering currency of content (for example, looking for recent updates, latest polls, upto-date analysis)

- finding and using historical data (past elections, polls, funding and so on) and to compare trends.

As a follow-up, each group was required to submit a summary of the website they were assigned to evaluate in class. These summaries were then added to a custom online library 'course guide'. In the following weeks, members of each group were asked to submit two additional web sources, each with corresponding annotations describing the source type and why/how it will be useful in tracking the campaigns. Students were encouraged to look for sources that would help 
their group in particular (that is, pertinent to the candidates to which they were assigned) as well as ones that would benefit the class as a whole. This content was added to the course guide by the librarian and shared with the class to consult as they continued their research throughout the semester.

\section{Information literacy threshold concepts}

The six IL threshold concepts, or frames, put forth in the aforementioned Framework include: Authority Is Constructed and Contextual, Information Creation as a Process, Information Has Value, Research as Inquiry, Scholarship as Conversation, and Searching as Strategic Exploration. Students were asked to reflect on their experiences and articulate the various IL strategies acquired and implemented through the study intervention during the course of their research assignment. Analysis of the research journals includes four of the six frames (Authority is Constructed and Contextual, Information Creation as a Process, Research as Inquiry, and Searching as Strategic Exploration), looking at select knowledge practices and/or dispositions that coincide with each (see Table 1).

Table 1: Information literacy frames used in student research journal analysis

\begin{tabular}{|c|c|}
\hline & $\begin{array}{c}\text { Knowledge Practices (Abilities) } \\
\text { Define different types of authority, such as subject expertise (for } \\
\text { example, scholarship), society position (for example, public office } \\
\text { or title) or special experience (for example, participating in a historic } \\
\text { event) - ACC 1 }\end{array}$ \\
$\begin{array}{c}\text { Authority Is } \\
\text { Constructed } \\
\text { and Contextual } \\
\text { (ACC) }\end{array}$ & $\begin{array}{l}\text { Recognise that authoritative content may be packaged formally or } \\
\text { informally, and may include audio, visual and other non-print } \\
\text { sources - ACC 2 }\end{array}$ \\
\hline
\end{tabular}




\begin{tabular}{|c|c|}
\hline & $\begin{array}{l}\text { Dispositions } \\
\text { - Motivate themselves to find authoritative sources, recognising that } \\
\text { authority may be conferred or manifested in unexpected ways - } \\
\text { ACC } 3\end{array}$ \\
\hline $\begin{array}{l}\text { Information } \\
\text { Creation as a } \\
\text { Process (ICP) }\end{array}$ & $\begin{array}{l}\text { Dispositions } \\
\text { - Value the process of matching an information need with an } \\
\text { appropriate product - ICP } 1\end{array}$ \\
\hline $\begin{array}{l}\text { Research as } \\
\text { Inquiry (RI) }\end{array}$ & $\begin{array}{l}\text { Knowledge Practices (Abilities) } \\
\text { - Employ critical skills to evaluate information - RI } 1 \\
\text { Dispositions } \\
\text { - Value persistence, adaptability and flexibility, and recognise that } \\
\text { ambiguity can be beneficial - RI } 2\end{array}$ \\
\hline $\begin{array}{l}\text { Searching as } \\
\text { Strategic } \\
\text { Exploration } \\
\quad \text { (SSE) }\end{array}$ & $\begin{array}{l}\text { Knowledge Practices (Abilities) } \\
\text { - Identify interested parties that might produce information about a } \\
\text { topic and how that information might be accessed - SSE } \mathbf{1} \\
\text { - Utilise divergent (for example, brainstorming) and convergent (for } \\
\text { example, selecting the best source) thinking appropriately when } \\
\text { searching - SSE } 2 \\
\text { - Design searches strategically, considering and selecting a system to } \\
\text { search and reviewing search results - SSE } 3 \\
\text { - Refine and adjust needs and search strategies during the process, as } \\
\text { needed, and apply results to new searches - SSE } 4 \\
\text { Dispositions } \\
\text { - Recognise the value of browsing and other serendipitous methods of } \\
\text { information gathering - SSE } \mathbf{5} \\
\text { - Actively seek out guidance from experts, such as librarians, } \\
\text { researchers and professors - SSE } \mathbf{6} \\
\text { - Understand that first attempts at searching don't always produce } \\
\text { adequate results - SSE } \mathbf{7} \\
\text { - Persist in the face of search challenges and know when to stop } \\
\text { searching - SSE } 8\end{array}$ \\
\hline
\end{tabular}

Authority is Constructed and Contextual (ACC) is a significant frame for this research project as students are searching for information that has not yet become a part of the canon of academia. As such, an understanding of the dependent and contextual nature of information 
construction is important. The analysis focuses primarily on students' motivation to locate authoritative information as well as their ability to define types of authority within the context of what is needed for the assignment.

The Information Creation as a Process (ICP) frame is primarily concerned with students' 'understanding that the purpose, message, and delivery of information are intentional acts of creation' and inclination to see the 'underlying processes of creation as well as the final product' (ACRL 2015). Many of the subcomponents to this frame, although relevant to IL in the study of politics, were found to go beyond what was being asked of students in this assignment. Therefore, just one disposition pertaining to 'matching an information need with an appropriate product' was used in the student journal analysis.

Research as Inquiry (RI) entails student's realisation that the research process is a cyclical one where the answers to questions spur the development of new and more intricate questions or new lines of research. As students are exploring the dynamic world of election information, they will use this frame as a means of taking stock of their changing information environment and use the information collected to elicit new streams of information. In the analysis of the student journals, we code recognition of research as an iterative process, students' ability to be self-directive in their inquiry, and embodying both persistence and flexibility in their research endeavours.

Finally, the Searching as Strategic Exploration (SSE) frame describes the act of 'searching' as being more than just Googling a topic. Students who demonstrate awareness and skill in this area understand that searching 'encompasses inquiry, discovery, and serendipity' and requires being able to identify 'possible relevant sources as well as the means to access those sources' (ACRL 2015). Our evaluative criteria for this frame includes an understanding that 
multiple search attempts may be needed for success, thoughtfulness regarding the information requirements of the assignment and how they will guide the search process, an exploratory attitude including the use of browsing to find information, and a willingness to reflect on information requirements and adapt incremental goals throughout the research process.

Student research reflections were coded for evidence of these abilities and dispositions. The researchers employed a modified inter-rater reliability procedure. This technique provides a means of triangulating findings in qualitative research. More than one person applies the research protocol to the data (in this case student journals) and the results are compared. Both researchers reviewed the journals individually. Differences in coding were then discussed. The final analysis is comprised of only those frames which appeared in both researchers' analysis.

\section{Information literacy and analysing election information literacy in the pre- and post-test surveys}

The goal of general education political science courses is to prepare students (many of whom are not political science majors) for citizenship by enabling them to become better consumers of political information and providing them with the skills needed to think and act strategically to achieve their political goals. To this end, fostering student confidence in finding information on public opinion, candidate backgrounds, campaign finance and predicting elections is a valuable endeavour in meeting course goals. This section provides an analysis of the pre-test surveys conducted at the onset of the quasi-experiment and the post-test surveys completed at the end of the prescribed intervention. The pre-test and post-test questionnaire make use of a five-point Likert scale where 'very confident' is indicated as 1 , and 'very unconfident' is indicated as 5. 
Analysis of the pre-test and post-test results indicates some difference in student confidence at the beginning of the research. Students in the treatment condition began the quasiexperiment with more confidence in their ability to navigate these various elements of election campaigns. When asked about finding public opinion information, students in the treatment condition reported feeling neither confident nor unconfident about their ability, while their counterparts in the control condition reported feeling somewhat unconfident. Similar patterns emerge on all the measures of confidence assessed. Treatment condition participants averaged a starting point of greater confidence concerning finding information about candidate backgrounds, campaign donations, assessing past and future election results. Students in the control condition were less likely to feel confident than their counterparts in the treatment condition.

The greatest source of anxiety in the pre-test for both groups was in finding information about campaign donations and predicting election results. When asked about their ability to find updated information on campaign donations, students in the treatment condition initially indicated that they were close to feeling uncertain. The average response was 2.85 on the Likert scale. Students in the control condition were less confident, with an average response of 3.5, expressing a sentiment between feeling neither confident nor unconfident and feeling somewhat unconfident. The reason for the difference in starting points of both groups is unclear. The data collected does not indicate a source for this gap in confidence. One possible source is the timing of the first survey in relationship to the course overview. Students in the treatment condition received an overview of the course including a basic description of the course goals and assignments (which included IL training and practicum) on the first day of classes, and they took the pre-test survey at the beginning of the third week of classes. While the course overview did 
not provide details about the assignment, the knowledge that it would be a part of the material covered in the course may have served to elevate confidence in their abilities. In any future study, the pre-test assessments should occur before a course overview.

Table 2 provides an overview of the pre- and post-test results assessing student confidence in finding information on public opinion, candidates' past public service, financial donations to campaigns, assessing the past and future election results. The analysis of the pre-test and post-test survey showed improvement in confidence for students in the control and treatment conditions. It is likely that exposure to course content in an introductory political science course improved students' confidence in navigating election information. However, among students in the control condition (who did not receive the intervention of an embedded librarian and information IL), only one measure of research confidence was statistically significant. On average students reported feeling .45 more confident (a change from 2.75 to 2.25 ) about their ability to find public opinion information from a variety of original sources. Students became more settled in their confidence about locating public opinion data. This finding was significant at the 5 per cent level.

Students in the treatment condition began the semester with weak feelings of certainty that they would be able to gather public opinion information from original sources. Responses to this question average about 2.5. By the end of the semester, these students were far more confident with an average question response of 1.6, ultimately falling between the sentiments of confident and very confident. The change in confidence is a large one with changes in average responses of .85 with statistical significance at the 10 per cent level. When asked how confident they were in finding information about whether an individual had served in public office, students with an embedded librarian and IL training began the year feeling confident. The 
average response for this group was 1.90. By the end of the semester, the average response to that question was 1.33 , a positive and statistically significant positive movement of .57 . The greatest change in confidence occurred in response to the question about students' ability to find up-to-date information about financial donations received by the candidate. At the beginning of the semester, IL students expressed very weak confidence with an average pre-test response of 2.85. However, in the post-test the average response was 1.80 , indicating a movement from weak confidence to stronger confidence. The change in sentiment is the most dramatic in the survey results in a positive movement of 1.05 points on the scale and was statistically significant at the level of 1 per cent. By contrast, control-condition students began the semester with much less confidence. The average pre-test response within that group was 3.5 , indicating a sentiment midway between uncertainty and feeling unconfident. Over the course of the semester, these students also grew in their confidence. The movement towards greater confidence was not as large (.20) and was not statistically significant.

When asked about their ability to predict election outcomes when they have knowledge of the candidates, treatment and control-condition students began the semester with very similar levels of confidence. That is, both groups felt uncertain (pre-test survey responses were 3.15 for the control group and 3.0 for the treatment group). By the end of the semester, there was a positive change of .15 for students without an embedded librarian and .76 for students with the embedded librarian. Over the course of the semester, students in the treatment condition become somewhat confident in their ability to predict elections while students in the control group remained uncertain. The change is statistically significant for only the treatment group at the 10 per cent level. 
Changes in student responses to past election results are not statistically significant for either group, but the patterns in the data persist. Students in the treatment condition began the semester with greater confidence in their abilities and experienced a larger positive change than their control-condition counterparts. Average pre-test results for the control group were 2.15 compared to 1.95 for treatment participants, indicating confidence in both groups. At the end of the semester, there was an average positive change of .38 in the treatment condition and .2 in the control condition.

Students in the control condition began the semester with greater anxiety about their ability to perform election-related research tasks while students in the treatment condition began the semester with slightly more confidence. Throughout the course of the semester, students in both the control and treatment conditions improved in levels of confidence for every task, suggesting a significant impact resulting from exposure to materials in the course. However, students with access to an embedded librarian and IL training experienced far greater gains in confidence, with results that were more likely to be statistically significant. Taken together, the results of the statistical analysis suggest that an embedded librarian and IL training have a positive impact on student feelings of confidence in the research process. The cultivation of assignments and selection of readings that result from the collaboration of a content expert and IL expert improve student perceptions of competence in engaging in election research tasks. 
Table 2: Student confidence in election research capability

\begin{tabular}{|l|l|l|l|l|}
\cline { 2 - 5 } \multicolumn{2}{l|}{} & \multicolumn{2}{|c|}{ Control } & \multicolumn{2}{c|}{ Treatment } \\
\cline { 2 - 5 } & Pre-test & Post-test & Pre-test & Post-test \\
\hline $\begin{array}{l}\text { How confident are you in your ability to find public } \\
\text { opinion information from a variety of original sources } \\
\text { regarding a candidate? }\end{array}$ & 2.70 & $2.25^{* *}$ & 2.50 & $1.65^{*}$ \\
\hline $\begin{array}{l}\text { How confident are you in your ability to find } \\
\text { information about whether an individual has served in } \\
\text { public office? }\end{array}$ & 2.25 & 1.90 & 1.90 & $1.33^{*}$ \\
\hline $\begin{array}{l}\text { How confident are you in your ability to find up-to-date } \\
\text { information about financial donations received by a } \\
\text { candidate? }\end{array}$ & 3.50 & 3.30 & 2.85 & $1.80^{* * *}$ \\
\hline $\begin{array}{l}\text { How confident do you feel predicting the outcome of a } \\
\text { given election where you have knowledge of the } \\
\text { candidates? }\end{array}$ & 3.15 & 3.00 & 3.00 & $2.24 *$ \\
\hline $\begin{array}{l}\text { How confident are you in your ability to find past } \\
\text { election results for a given state? }\end{array}$ & 2.15 & 1.95 & 1.95 & 1.57 \\
\hline
\end{tabular}

\section{Analysis of research journals}

In addition to the quasi-experiment, this article reports the content analysis of student journals.

Journals were analysed using the framework for IL in higher education. Content analysis offers a set of tools for evaluating a body of communication such as text, speech or film to understand its meaning. In this method, the researcher or coder analyses the communication for concepts relevant to the research question. These concepts or codes are identified, and their relationship to each other and the rest of the text is explored. Content analysis does not predominate in the field of IL. It is not identified as a method in any of the 122 articles assessed by Koufogiannakis and Wiebe (2006). Content analysis may be more appropriate for understanding the internalisation of 
IL concepts than self-reporting or faculty grading alone. By utilising content analysis, researchers can uncover specific evidence of skills and attitude acquisition. In this analysis, specific knowledge practices are identified as individual codes in student reflections of their research endeavours.

Coding the research journals proved to be a valuable exercise, revealing many insights to students' information-seeking processes and the extent to which IL skills and habits came into play as they researched their candidates and related issues. The control group did not participate in this part of the study, thus eliminating the possibility of direct comparison. However, the written reflections of those in the experimental group serve well to complement the survey results (see Table 3 ).

\section{Authority is Constructed and Contextual (ACC)}

A total of 18 journal passages exemplified one of the knowledge practices or dispositions being looked for in this frame. The majority $(n=14)$ fell under ACC 3, with students affirming the disposition of being motivated to find authoritative sources. Comments ranged from students simply expressing how they paid special attention to who wrote a particular article to others offering more detailed explanation of how they considered what made a source authoritative and, therefore, more 'reliable', 'credible' or 'trustworthy'. Many cited individual author credentials while others determined authority by looking at source sponsors or corporate authors. Seven students mentioned looking at website URLs (such as .gov, .org., .edu) to make authority judgments. 


\section{Information Creation as a Process (ICP)}

Eleven students reflected on their efforts to match source choices with their specific information need (ICP 1) - the one disposition selected for analysis in this frame. Most groups seemed to have divided up the research tasks, therefore making this 'need' different for each student. As one student stated: 'In effort of collecting and analysing data, one must first determine what kind of information is necessary'. Several comments alluded to this being a particularly challenging task. Referring to her assigned research task, one student recalled having 'trouble making sure that the site I had chosen was the right one for me'. Another student clearly articulated what type of information was not needed for a specific part of the project ('news articles') and what was needed ('polls and statistics about candidates spending habits and the issues they supported'). After bringing up information from both Google Scholar and the library's main search portal, a student concluded that although 'these types of sources are valid, they just were not suitable for this project'.

\section{Research as Inquiry (RI)}

Journal passages coded for the Research as Inquiry frame evinced students' attempts at evaluating information critically (RI 1) or demonstrating a persistent and flexible approach to searching (RI 2). Thirteen comments were identified as possessing attributes suitable for this frame, with all but one falling under RI 1. Here, students explained how they scrutinised information similar to the ways they did with regards to 'authority', but more so evaluating the content itself, rather than the merits of the source creator/author. Oft-mentioned strategies for evaluating information in this way included: considering currency/date of information, checking for citations or links to original data or statements. 


\section{Searching as Strategic Exploration (SSE)}

It was from this final frame that the greatest number of knowledge practices and dispositions (8) were identified as being appropriate categories for analysis in the current study. Of these, it is SSE 3, 'Design searches strategically, considering and selecting a system to search and reviewing search results', that best epitomises the frame as a whole. Not surprisingly, then, did the greatest number of coded responses (14) fall under this column. The most prevalent strategy involved using Google's advanced search features to construct more intentional, targeted queries. Nine students made reference to implementing this technique. Others outlined the ways in which they thought critically about how and where they searched and what search terms they used and found most useful. Five students noted the value of the help they sought out and received by consulting either the course professor, librarian, or peers that they held in high esteem (SSE 6). Additionally, five students expressed how they struggled to find the information they were looking for, but were successful after several attempts (SSE 8).

Table 3: Student journals mapped to selected information literacy frames

\begin{tabular}{|c|c|c|}
\hline \multirow{2}{*}{ Authority is Constructed and Contextual (ACC) } & ACC 1 & 2 \\
\cline { 2 - 3 } & ACC 2 & 2 \\
\cline { 2 - 3 } & ACC 3 & 14 \\
\hline Information Creation as a Process (ICP) & ICP 1 & 11 \\
\hline \multirow{2}{*}{ Research as Inquiry (RI) } & RI 1 & 12 \\
\cline { 2 - 3 } & RI 2 & 1 \\
\hline \multirow{2}{*}{ RSE 1 } & 1 \\
\cline { 2 - 3 } & SSE 2 & 0 \\
\hline
\end{tabular}




\begin{tabular}{|c|c|c|}
\hline \multirow{4}{*}{ Searching as Strategic Exploration (SSE) } & SSE 3 & 14 \\
\cline { 2 - 3 } & SSE 4 & 1 \\
\cline { 2 - 3 } & SSE 5 & 3 \\
\cline { 2 - 3 } & SSE 6 & 5 \\
\cline { 2 - 3 } & SSE 7 & 3 \\
\cline { 2 - 3 } & SSE 8 & 5 \\
\hline
\end{tabular}

\section{Discussion}

Introductory political science courses often seek to formalise students' civic engagement by surveying a wide range of topics important to citizenship. They also seek to equip students with the skills needed to navigate the political world over a lifespan. The task is daunting. However, the need for this training is increasingly great as the media landscape becomes more fragmented, exposing students to increasingly diverse sources of information without clear markers indicating the origin of content, objective presentation of evidence and the purpose of writing. As young people rely increasingly on social media as a primary news source, and traditional news outlets undertake marketing techniques such as embedded advertisement which blur the lines of journalism and advocacy, the ability to interrogate information they receive becomes increasingly important. Embedding a librarian in a course and integrating IL training into the course assignments offer a way to meet this increasing need for media savvy among students. The results of the quasi-experiment demonstrate the positive effects that integration of an embedded librarian and IL training can have on student confidence in undertaking election research. The analysis of student journals also demonstrates benefits beyond confidence. It suggests that integration of IL training in a political science course allows students to adopt 
practices and attitudes that positively contribute to their ability to interrogate important information.

Advocates such as Shapiro and Hughes (1996) have suggested IL as a central aspect of a liberal education in the digital age. While having little impact on traditional classroom learning, IL may advance the skills needed in the modern classroom. There is little evidence to suggest that IL significantly advanced students' ability to memorise content from a textbook. However, very little of the activities in a modern political science classroom is dedicated to rote memorisation. Pedagogical trends in the discipline focus on critical thinking skills (Fitzgerald and Baird 2011; Olsen and Statham 2005), and the application of theory. These activities require that students can find and properly categorise new information. These elements are at the forefront of efforts to engage students in preparation for citizenship.

Students' perception of their research capability is an important aspect of this conversation. While measures of perception alone are insufficient to indicate the acquisition of a skill, they are an important precursor to student engagement in that ability. In other words, if students believe that they are unable to find and assess information about the political world they will be less inclined to try. As such, the measures of confidence explored in this research give insight into the impact of IL on student ability to navigate the political information they seek. Thus, the research lens offers broad support for the idea that combining an embedded librarian with IL training has a positive impact on students' assessment of their research ability. This pedagogical technique is a helpful precursor to student engagement and exploration of political information. When compared to students in a traditional introductory course, students engaged in IL practices have an advantage in the growth of their confidence over the course of the semester. 
Students with an embedded librarian reported greater levels of confidence in finding public opinion data, candidates' past service in office, campaign donation information and in predicting elections. This confidence may transfer well to other tasks within the discipline. Once students feel confident accessing information about public opinion on elections, they may be able to transfer this ability to other topics such as social policy, attitudes towards defence spending and so on. The integration of an embedded librarian and IL training and emphasis within the course may support learning beyond the assignment to which it is geared. Similarly, once students have navigated the murky waters of finding information about campaign donations they are well positioned to follow the money trail in other issues as well. While the current study assesses confidence within the limited scope of elections, the possibility of impacts in another topic of study is intriguing.

The analysis of student journals offers important insights into discipline-specific knowledge. Student internalisation of knowledge-building attitudes and practices are a central component of IL. The journals produced by students in the quasi-experiment provide evidence that students acquired multipurpose research skills and strategies. The IL practices observed in student journals highlight several elements that are central to knowledge in political science, for example a wide variety of strategies in determining the authority of a source. Whether through an emphasis on credentials, source type or sponsorship, student engagement with issues of the reliability and credibility of sources fosters critical thinking skills that are central to disciplinary goals as wide ranging as an understanding of the research and advocacy of interest groups to questions of issue publics and opinion leadership. These practices support a hierarchical understanding of knowledge that privileges verified information, evidence-based practices and scientific inquiry. 
Another example of this is seen in the use of searching as strategic exploration frame operationalised in student journals. This skill is central to the research tasks widely assigned to students in the discipline of political science. This approach to research allows students to sort through the vast array of detailed information entailed in such tasks as writing a literature review, accessing government documents and writing research papers. These tasks allow students to both understand the breadth of a particular topic and also narrow in on specific elements such as schools of thoughts, dominant methodologies employed and so on. These skills are also applied equally well to general inquiry in the political world. Implementation of these practices is evident throughout student journals in their ability to reference and operationalise the frames inserted in the IL training.

\section{Conclusion}

Combining the IL expertise of an embedded librarian and the content knowledge of an expert in the discipline offers a unique opportunity for introductory course instructors in the discipline of political science. It allows students not only to master the basics of research in ways that are targeted towards the specific activities in which majors engage but also foster critical thinking skills that will allow them to engage political content thoughtfully as non-majors. Our research suggests that the training and resources provided by an embedded librarian increase student confidence in their ability to find information about and predict the outcome of elections when they have the required data.

Further research is needed to determine the longevity of the IL training effect (a longterm need in the field). There is reason to suspect that the skills learnt are transferable and thus may outlast the assignment, however a follow-up study that gauges continued student use of IL 
techniques as well as a journal assignment which explores their operationalisation of these strategies is warranted. The extension of the IL training to other topics and classes is another area of interest. Having used IL to gain more information about elections, are students better placed to find information about the legislative process or the tax code? Findings that support the transferability of the effect would strengthen arguments for greater attention to IL within general education curricula.

The growing complexity of the information marketplace in which students live and work necessitates an approach to learning that helps them parse through large quantities of data. A course-embedded librarian may represent the best option for integrating the skills and attitudes required for this competency. An embedded librarian and IL training offer one avenue to address this concern. They make use of existing resources within the academy through partnerships that lessen the potential burden on content experts while improving student research outcomes. With the evidence presented here suggesting that these techniques may improve student research confidence and research strategies, incorporation of IL and collaboration with library faculty should receive further attention in the discipline of political science. 


\section{References}

Association of College and Research Libraries (ACRL) (2000) Information Literacy Competency Standards for Higher Education, http://www.ala.org/acrl/standards/informationliteracycompetency

Association of College and Research Libraries (ACRL) (2015) Framework for Information Literacy for Higher Education, http://www.ala.org/acrl/standards/ilframework

Alexander, R. (2009) 'Political literacy as information literacy', Communications in Information Literacy 3, no. 1: 9-13.

Bowler, M. and Street, K. (2008) 'Investigating the efficacy of embedment: Experiments in information literacy integration', Reference Services Review 36, no. 4: 438-449.

Butera, G., Gomes, A. and Kakar, S. (2014) ‘Expanding our roles: Embedded in curriculum design’, Medical Reference Services Quarterly 33, no. 3: 292-301.

Cope, J. and Flanagan, R. (2013) 'Information literacy in the study of American politics: Using new media to teach information literacy in the political science classroom', Behavioral \& Social Sciences Librarian 32, no. 1:3-23.

Corasaniti, N. and Parker, A. (2014) 'G.O.P. ads chase voters at home and on the go', The New York Times, 1 November, https://www.nytimes.com/2014/11/01/us/politics/gop-ads-chasevoters-at-home-and-on-the-go-.html?_r=0 (accessed 16 April 2017).

Daugherty, A. L. and Russo, M.F. (eds) (2013) Embedded Librarianship: What Every Academic Librarian Should Know, Santa Barbara, CA: Libraries Unlimited.

Fitzgerald, J. and Baird, V. A. (2011) 'Taking a step back: Teaching critical thinking by distinguishing appropriate types of evidence', PS: Political Science \& Politics 44, no. 3: $619-624$. 
Gibson, C. (2008) ‘The history of information literacy’, in C.N. Cox and E. Blakesley (eds) Information Literacy Instruction Handbook, Chicago: Association of College and Research Libraries, 10-25.

Gilbert, J.K., Knutson, K. and Gilbert, C.P. (2012) 'Adding an integrated library component to an undergraduate research methods course', PS: Political Science \& Politics, 45, no. $1: 112-118$.

Helms, M. and Whitesell, M. (2013) 'Transitioning to the embedded librarian model and improving the senior capstone business strategy course', Journal of Academic Librarianship 39, no. 5: 401-413.

Kapitzke, C. (2003) 'Information literacy: A positivist epistemology and a politics of outformation', Educational Theory 53, no. 1: 37-53.

Knapp, J. A., N. J. Rowland and E. P. Charles (2014), 'Retaining students by embedding librarians into undergraduate research experiences', Reference Services Review 42, no. 1: $129-147$.

Koufogiannakis, D. and N. Wiebe (2006), 'Effective methods for teaching information literacy skills to undergraduate students: A systematic review and meta-analysis', Evidence Based Library and Information Practice 1, no. 3: 3-43.

Law and Political Science Section, ACRL (LPSS) (2008) Political Science Research Guidelines, http://www.ala.org/acrl/sites/ala.org.acrl/files/content/standards/PoliSciGuide.pdf

Marfleet, B.G., Dille, B.J. and Dille, B.J. (2005) 'Information literacy and the undergraduate research methods curriculum', Journal of Political Science Education, 1, no. 2: 175-190.

Olsen, J., and Statham, A. (2005) 'Critical thinking in political science: Evidence from the 
introductory comparative politics course', Journal of Political Science Education 1, no. 3: $323-344$.

Owusu-Ansah, E. K. (2003) 'Information literacy and the academic library: A critical look at a concept and the controversies surrounding it', The Journal of Academic Librarianship 29, no. 4: 219-230.

Pritchard, P. A. (2010) 'The embedded science librarian: Partner in curriculum design and delivery', Journal of Library Administration 50, no 4: 373-396.

Shapiro, J.J. and Hughes, S.K. (1996) 'Information literacy as a liberal art: Enlightenment proposals for a new curriculum', Educom Review, 31, no. 2: 31-35.

Shumaker, D. (2009) 'Who let the librarians out? Embedded librarianship and the library manager', Reference \& User Services Quarterly 48, no. 3: 239-257.

Shumaker, D. (2012) The Embedded Librarian: Innovative Strategies for Taking Knowledge where it's Needed, Medford, NJ: Information Today.

Smith, A. (2014) 'Cell phones, social media and campaign 2014', Pew Internet Research Project, http://www.pewinternet.org/2014/11/03/cell-phones-social-media-and-campaign2014/

Spiranec, S., Zorica M.B. and Kos, D. (2016) 'Information literacy in participatory environments: The turn towards a critical literacy perspective', Journal of Documentation 72, no. 2: $247-264$.

Stevens, C. R. and P. J. Campbell (2008), 'Collaborating with librarians to develop lower division political science students' information literacy competencies', Journal of Political Science Education 4, no. 2: 225-252.

Tewell, E. (2015) 'A decade of critical information literacy: A review of the literature', 
Communications in Information Literacy 9, no. 1: 24-43.

Thornton, S. (2006) 'Information literacy and the teaching of politics', LATISS: Learning and Teaching in the Social Sciences 3, no. 1: 29-45.

Thornton, S. (2008) 'Pedagogy, politics and information literacy', Politics 28, no. 1: 50-56.

Thornton, S. (2010) 'From "scuba diving” to "jet skiing”? Information behavior, political science, and the Google generation', Journal of Political Science Education 6, no. 4: 353368.

Thornton, S. (2012) 'Trying to learn (politics) in a data-drenched society: Can information literacy save us?', European Political Science 11, no. 2: 213-223.

Webber, S. and Johnston, B. (2000) 'Conceptions of information literacy: New perspectives and implications', Journal of Information Science 26, no. 6: 381-397.

Williams, M.H. and Evans, J.J. (2008) 'Factors in information literacy education', Journal of Political Science Education 4, no. 1: 116-130.

Williams, M. H., K. A. Goodson and W. G. Howard (2006), 'Weighing the research paper option: The difference that information literacy skills can make', PS: Political Science \& Politics 39, no. 3: 513-519. 